\title{
Prognostic factors of survival in Moroccan patients with Glioblastoma
}

\author{
Said Hilmani ${ }^{1}$, Abdelhamid Barakat ${ }^{2}$, Abdennabi EL Kamar ${ }^{1}$, Abdessamad EL Azhari ${ }^{1}$, Omar Abidi ${ }^{3}$ \\ 1. Service de Neurochirurgie, Centre Hospitalier Universitaire Ibn Rochd, Casablanca, Morocco. 2. Laboratoire de \\ Génétique Moléculaire Humaine, Département de la Recherche Scientifique, Institut Pasteur du Maroc, Casablanca, \\ Morocco. 3. Institut Supérieur des Professions Infirmières et Techniques de Santé (ISPITS), Casablanca, Morocco.
}

Correspondence: Omar Abidi. Address: Institut Supérieur des Professions Infirmières et Techniques de Santé (ISPITS), Rue Faidouzi Mohamed, Casablanca, Morocco. Email address: o.abidi@yahoo.fr

Received: September 17, 2013 Accepted: November 18, 2013

DOI : $10.5430 /$ jst.v4n1p42

URL: http://dx.doi.org/10.5430/jst.v4n1p42

Online Published: January 5, 2014

\section{Abstract}

Background: Glioblastoma is the most common and aggressive type of glioma and has the poorest survival. Some parameters have been identified as potential prognostic factors for patients with glioblastoma. The purpose of this study is to examine the influence of clinical, tumor and treatment factors on overall survival in Moroccan patients with newly diagnosed glioblastoma.

Methods: In this study, we retrospectively analyzed data from 89 Moroccan patients with newly diagnosed Glioblastoma (54 males and 35 females). The effect of different prognostic factors on survival was evaluated using Kaplan-Meier method and log rank test for univariate analysis; and Cox regression method for multivariate analysis to identify the independent prognostic factors.

Results: The Median age of patients at diagnosis was 52 years (range 11-84 years) and the male/female ratio was 1.54/1. The median of pre-operative Karnofsky Performance Score (KPS) was 70 (95\% CI: 60-70) and the median overall survival was 12 months (95\%: 9-13 months). According to univariate analysis, age ( $p=0.0088)$, KPS $(p=0.0001)$ and radiation treatment $(p<0.0001)$ parameters were significantly associated with survival. In addition, the tumor size, KPS and radiotherapy parameters were significantly associated with survival in multivariate Cox analysis $(p<0.05)$. However, extent of tumor resection, gender, chemotherapy and clinical history delay factors were not found significant in both analyses $(p>0.05)$.

Conclusion: Our results showed the strong prognostic value of age, performance score, and treatment with radiotherapy for glioblastoma patients validating the results published in previous studies. This work could contribute towards informing further research on prognostic variables for patients with glioblastoma.

\section{Key words}

Glioblastoma, Prognosis factors, Univariate and multivariate analyses, Outcome, Moroccan patients

\section{Introduction}

Glioblastoma (GBM) is the most frequent and aggressive primary brain tumor in humans, with up to $50 \%$ of all primary brain gliomas and an annual incidence of approximately 3 in 100,000 people newly diagnosed each year in US and 
European countries ${ }^{[1,2]}$. According to the latest WHO classification, GBM can be divided into various subtypes. Primary GBMs, arise de novo and occur mostly in older age groups, with shorter survival time, and are more frequently compared to secondary GBMs that progress from astrocytomas of lower grade ${ }^{[3,4]}$. Although the median age of GBM patients is $>60$ years, GBM occurs in individuals of any age ${ }^{[5]}$. After initial diagnosis, the standard treatment consists of surgery with maximal feasible resection, post-operative fractionated external beam radiation with concomitant and adjuvant chemotherapy with temozolamide. The addition of temozolamide has been shown to improve overall survival ${ }^{[6,7]}$. Despite recent advances in treatment including surgical resection followed by radiotherapy and chemotherapy, the prognosis of patients with GBM remains poor with a median survival of 9 to 15 months ${ }^{[6]}$. The treatment difficulty is due to the exceptionally infiltrative nature of GBM and its proclivity to integrate into normal brain tissue ${ }^{[8]}$. The patients who survive more than three years after the diagnosis are described as long term survivors ${ }^{[9]}$. It has been suggested that the better outcomes observed in this group of patients could be related to clinical, tumor and/or treatment related factors ${ }^{[10]}$. Several factors, clinical (age, performance status), therapeutic (quality of surgery, radiotherapy, chemotherapy) and tumor characteristics (size, location and primary or secondary), have already been studied to investigate their influence on outcomes. Indeed, younger age, good Karnofsky performance status (KPS) at the time of diagnosis, radiotherapy, histology and extent of tumor resection have been identified as potential prognostic factors for patients with $\mathrm{GBM}^{[5,11-18]}$. In a previous study, we analyzed TP53 and IDH1-2 genes in 34 GBM cases ${ }^{[19]}$. Here we attempted to clarify the prognostic value of some clinical, therapeutic and tumor parameters noted in Moroccan GBM patients.

\section{Materials and methods}

We conducted a retrospective analysis of data from 89 patients with newly diagnosed GBM who were recruited and followed at the neurosurgery department of Ibn Roch hospital, in Casablanca city, between January 2004 and June 2010. The diagnosis of glioblastoma was confirmed as per World Health Organization (WHO) guidelines.

To evaluate prognostic factors for overall survival, all the information was collected and recorded in a personal database from the paper and electronic medical records. Variables analyzed were age, gender, extent of surgery, tumor location, clinical history delay (the time in months between onset of the first clinical symptoms and diagnosis of Glioblastoma), tumor size, treatment (radiotherapy, chemotherapy or any treatments), overall survival and KPS (a performance measure for rating the ability of a person to perform usual activities, evaluating a patient's progress after a therapeutic procedure. There are different values of KPS $(0,10,20,30,40,50,60,70,80,90$ and 100) according the ability of a person to perform usual activities).

Tumor resection status was classified by a multidisciplinary tumor team on the basis of post-operative CT scan of the brain performed within the first week after surgery. Extent of excision was defined as complete (no residual tumor tissue), subtotal ( $>75 \%$ of tumor removed), partial ( $<50 \%$ of tumor removed) and biopsy (stereotactic biopsy only). Overall survival was measured from the date of surgery to the date of death, to the date of withdrawing from the study or to the final analysis.

After collection of clinical, pathological and treatment data, we divided the patients on the basis of each variable into sub-groups to determine their impact on survival: (KPS $\geq 80$ and KPS $<80$ ), (age $<60$ and age $\geq 60$ years), (male and female), (biopsy, partial, subtotal and total resection) (clinical history delay $\leq 3$ and $>3$ months), (tumor size $\leq 40$ and $>40$ $\mathrm{cm} 3$ ) and (radiotherapy, chemotherapy and no treatment) sub-groups. The univariate median survival time was analyzed by constructing probability curves according to the Kaplan-Meier method and comparing these using the log-rank test.

To determinate independent predictors of survival, the prognostic factors were then introduced in Cox proportional hazard model (multivariate analysis) with a backward selection procedure and a removal criterion $p>0.10^{[20]}$.

All calculations were done using MedCalc software (version 12.2.1) and p-values of $<0.05$ were considered as significant. 


\section{Results}

Among 89 GBM patients, 54 were male and 35 were female with a male predominance (male:female ratio was 1.54:1). The median age at time of diagnosis was 52 years (range 11-84 years, 95\% CI: 47.78-56) for all patients, was 48 years for females and was 54.5 years for males. The median KPS was 70 (95\% CI: $60-70)$ with $62 \%$ of patients had a KPS of at least 70 and $38 \%$ of them had a KPS greater than or equal to 80 . The mean of clinical history delay was 3.84 months $(95 \%$ CI: 2.90-4.79) and the tumor size median was $44 \mathrm{~cm} 3$ (95\% CI: 35.70-51.20). Total tumor resection was performed in 12 cases (13.48\%), subtotal and partial resections in 23 patients (25.84\%) for each, and stereotactic biopsy in 31 patients (34.83\%). Fifty patients (56.18\%) received only radiotherapy, 21 (23.60\%) received combined radio-chemotherapy and $18(20.22 \%)$ patients didn't receive any treatment. Radiotherapy was performed with a total dose of $60 \mathrm{~Gy}$ ( $2 \mathrm{~Gy} / \mathrm{fraction})$ and chemotherapy was administered concomitantly, combining Platamine $(50 \mathrm{mg} / \mathrm{week})$ and Oncovin $(2 \mathrm{mg} / \mathrm{week})$ or Carmustine (BCNU) (100-200mg/6weeks) and only two patients were benefited of Temozolomide. Tumor locations are displayed in Table 1. Overall median survival was 12 months (95\% CI: 9-13) for all patient, 11 months for females and 13 months for males.

Table 1. Location of tumors in various parts of the brain

\begin{tabular}{lll}
\hline Location & Number & Percentage (\%) \\
\hline Temporo-parietal (TP) & 23 & 25.80 \\
Frontal (F) & 19 & 21.35 \\
Parietal (P) & 13 & 14.61 \\
Fronto- parietal (FP) & 9 & 10.11 \\
Occipital (O) & 7 & 7.88 \\
Temporal (T) & 7 & 7.88 \\
Fronto-temporal (FT) & 4 & 4.50 \\
Parieto-occipital (PO) & 4 & 4.5 \\
Temporo-occipital (TP) & 3 & 3.37 \\
\hline Total & 89 & 100 \\
\hline
\end{tabular}

Univariate analysis of prognostic parameters showed favorable prognostic value for overall survival of patients age $<60$ years compared to patients age $\geq 60$ (survival median 13 vs. 7.5 months; $p=0.0088$ ), patient pre-operative KPS $\geq 80$ compared to KPS $<80$ (survival median 24 vs. 8 months; $p=0.0001$ ); and radiotherapy compared to chemotherapy and absence of treatment (survival median 18 vs. 13 and 5 months; $p<0.0001$ ) (Table 2) (Figure 1). However, this analysis showed that gender, extent of surgery, clinical history delay and tumor size were not found to be statistically significant predictors for overall survival $(p>0.05)$ (Table 2).

The results of multivariate analysis are displayed in Table 2. The following parameters were identified as independent factors: patient KPS $(p=0.0014)$ and radiotherapy $(p<0.0001)$ as categorical variables. The instantaneous relative risk of death was 2.8 (95\% CI: 1.4930-5.2513) for a patient with lower KPS $(<80)$ compared with a patient with higher KPS $(\geq$ $80)$ and 4.21 (95\% CI: 2.1384-8.2862) for a patient not treated with radiation compared with a patient treated with radiation. In the multivariate analysis, the tumor size was examined as a continuous variable and was also found as independent factor $(p=0.0240)$ with a relative risk of instantaneous death of 0.9904 (95\% CI: 0.9822-0.9987) for an individual with an increase of 1 in the value of tumor size compared with another individual. 
Table 2. Clinical, treatment and tumor factors associated with overall survival time of patients with glioblastoma in univariate and multivariate analyses

\begin{tabular}{|c|c|c|c|c|c|c|}
\hline $\begin{array}{l}\text { Prognostic } \\
\text { factors }\end{array}$ & $\begin{array}{l}\text { Sub- } \\
\text { groups }\end{array}$ & No. & $\begin{array}{l}\text { Median survival } \\
\text { (months) }\end{array}$ & $\begin{array}{l}\text { Log-rank } \\
\text { test } \\
\text { (p-value) }\end{array}$ & $\begin{array}{l}\text { Cox regression } \\
\text { analysis } \\
\text { (p-value) }\end{array}$ & $\begin{array}{l}\text { Hazard ratio } \\
(95 \% \mathrm{CI})\end{array}$ \\
\hline \multirow[t]{2}{*}{ Age (years) } & $<60$ & 61 & 13 & 0.0088 & NS & \\
\hline & $\geq 60$ & 28 & 7.5 & & & \\
\hline \multirow[t]{2}{*}{ Gender } & Male & 54 & 13 & 0.3111 & NS & \\
\hline & Female & 35 & 11 & & & \\
\hline \multirow[t]{2}{*}{ KPS } & $<80$ & 55 & 8 & 0.0001 & 0.0014 & 2,8000 \\
\hline & $\geq 80$ & 34 & 24 & & & $(1.4930-5.2513)$ \\
\hline \multirow{4}{*}{$\begin{array}{l}\text { Extent of } \\
\text { surgery }\end{array}$} & Biopsy & 31 & 12 & 0.2445 & NS & \\
\hline & Partial & 23 & 13 & & & \\
\hline & Subtotal & 23 & 11 & & & \\
\hline & Total & 12 & 14 & & & \\
\hline \multirow{2}{*}{$\begin{array}{l}\text { Clinical } \\
\text { history } \\
\text { delay }^{*}\end{array}$} & $\leq 3$ & 58 & 12 & 0.4901 & NS & \\
\hline & $>3$ & 31 & 13 & & & \\
\hline \multirow{2}{*}{$\begin{array}{l}\text { Tumor size } \\
\left(\mathrm{cm}^{3}\right)\end{array}$} & $\leq 40$ & 39 & 12 & 0.5013 & $0.0240^{\#}$ & 0,9904 \\
\hline & $>40$ & 43 & 13 & & & $(0.9822-0.9987)$ \\
\hline \multirow{3}{*}{ Treatment } & $\mathrm{RT}$ & 50 & 18 & $<0.0001$ & $<0.0001$ & 4,2094 \\
\hline & $\mathrm{RT}+\mathrm{CHT}$ & 21 & 13 & & & $(2.1384-8.2862)$ \\
\hline & No & 18 & 5 & & & \\
\hline
\end{tabular}

\# : The tumor size parameter was entered as a continuous covariate in Cox regression analysis

*: Time (in months) between onset of the first clinical symptoms and diagnosis of Glioblastoma

NS: Not significant, KPS: Karnofsky Performance Score, RT: radiotherapy, CHT: Chemotherapy, No: non treatment

\section{Discussion}

Glioblastoma is the most frequent and aggressive primary brain tumor in humans and despite recent advances in treatment including surgical resection followed by radiotherapy and chemotherapy, the prognosis of patients with GBM remains poor with a median survival of 9 to 15 months after diagnosis ${ }^{[6,21]}$. In the present study, we investigated possible prognostic factors associated to improvements in overall survival for Moroccan patients with glioblastoma. The results demonstrated that the age, KPS and radiotherapy factors were significantly associated with overall survival in univariate analysis, and that the KPS, radiotherapy and tumor size (as a continuous variable) factors were identified as independent factors of patient survival in multivariate analysis. However, extent of tumor resection, gender, chemotherapy and clinical history delay factors had no significant influence on overall survival in both analyses.

It is well known that men are more likely to suffer from glioblastoma compared to women. The male:female ratio ranges from 1.2:1 to $2.1: 1^{[12,22-24]}$. In accordance with these studies there is a higher incidence of GBM in men than women in our study (male:female ratio $=1.54$ ). Although there is a preponderance of the male gender, the results exclude gender parameter as prognostic factor of survival ${ }^{[22,23,25]}$.

To date, the most important prognostic factors of survival in patients with newly diagnosed glioblastomas are age at diagnosis and Karnofsky performance score ${ }^{[10,12,16,26-29]}$. Our findings reaffirmed them as factors influencing the overall 
survival. In fact, we found that younger patients ( $<60$ years) had significantly longer survival than older patients $(\geq 60$ years) with a median overall survival of 13 vs. 7.5 months $(p=0.0088)$, respectively. Similar results were reported by Balducci et al ${ }^{[30]}$ with a median overall survival of $21 \mathrm{vs.} 14$ months in young ( $<65$ years) compared to elderly ( $\geq 65$ years) patients $(p=0.01)$. Surawicz et al revealed that 5 -year overall survival was $21,10.3$ and 0.2 months in patients ages, 15 - 24 years, $35-44$ years and $65-74$ years, respectively after analysis of more than 18000 patients with glioblastoma ${ }^{[31]}$.
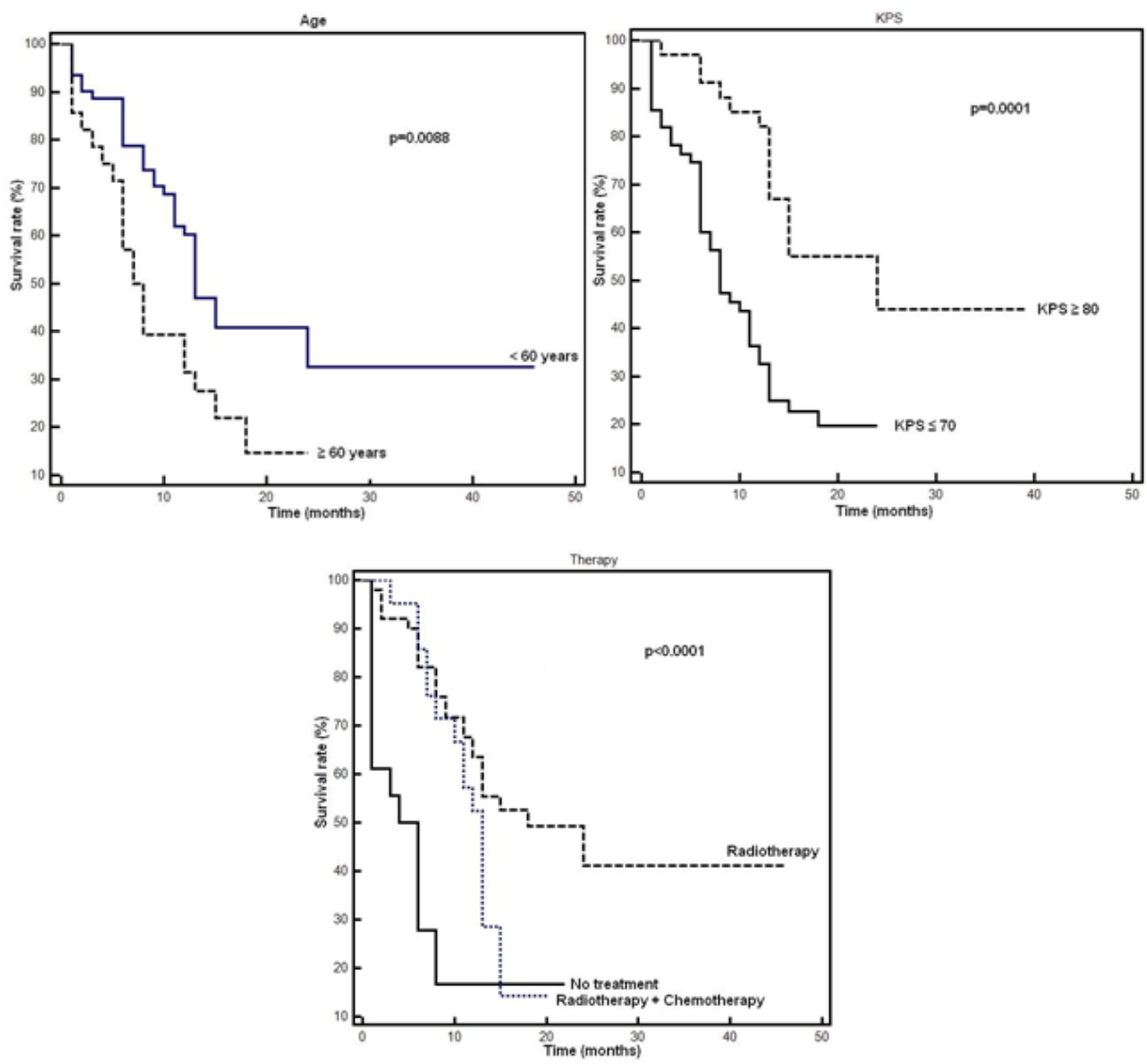

Figure 1. Kaplan-Meier survival curves for significant prognostic factors in glioblastoma patients, age, KPS and radiotherapy. The p-value was derived using log rank test

Like other studies, in the present work, age group lost its significance as an independent variable when it entered in the multivariate analysis ${ }^{[32,33]}$. It has been reported that possible lower immunocompetence, resistance to adjuvant therapy and age associated comorbidities in elderly patients may be a predisposing factor to adverse outcomes ${ }^{[24,30,34]}$. In addition, the present analysis confirmed that patients who had higher KPS scores on admission showed survival advantage in both univariate and multivariate analyses. The overall survival was 24 months in our patients who had KPS $\geq 80$ vs. 8 months only in patients with KPS $<80$ with a hazard ratio (HR) of 2.8 (95\% CI: 1.4930-5.2513) for the last group. The same outcome was reported by the majority of previous studies ${ }^{[11,12,22,23,27]}$. Lacroix et al found that patients with a KPS $\geq 80$ had a median survival of 11.2 months as opposed to 8.8 months in the less fit patients with a HR of 1.4 (95\% CI: $1.1-1.8$ ) [11] and Li et all reported a median survival of 20 months in patients with KPS $\geq 80$ vs. 10 months with HR of 0.283 (95\% CI: $0.140-0.571$ ) for KPS $\geq 80$ relative to KPS $<80^{[27]}$. The KPS has been designed for cancer patients to measure the level of patient activity and medical requirements ${ }^{[35]}$.

The role of radiotherapy in the treatment of glioblastoma is unchallenged ${ }^{[36]}$. The present study also proved the assertion that radiotherapy would prolong the survival and had independently influence on it. We also found that radiotherapy was a more significant prognostic factor than age and KPS, meaning that radiotherapy represents a criterion with a greater 
influence on survival. Our suggestions confirm those reported by Mineo et al 2007 who also revealed that the influence of radiotherapy on survival was greater than the influence of age ${ }^{[16]}$. Also, it has been suggested that the hypofractionated radiotherapy can be a safe and effective option in the treatment of GBM in elderly patients with a KPS $>70^{[37,38]}$. Additionally, Johnson et al revealed that patients not treated with radiation therapy had extremely poor prognoses, with a median survival following diagnosis of approximately 3 months ${ }^{[39]}$. On the other hand, it has been concluded that the combined effect of RT and chemotherapy is effective in young patients but also in elderly patients with KPS $>70$ and few Co-morbidity ${ }^{[16,30,32,34,40,41]}$. However, our patients who underwent combined radio/chemotherapy had a shorter survival time than patients who were treated by radiation alone. This could be explained in part by the fact that our patients received different chemotherapeutic regimens compared to those reported in the literature who received a homogenous chemotherapeutic regimen. In this regards, Mineo et al 2007 suggested that the parameter "chemotherapy" is probably not precise enough to evaluate the efficacy of such treatment, as the results of different protocols are merged, thus rendering the result of a better protocol undetectable by means of this simple criterion. In addition, separate analysis is difficult because the number of patients is decreasing and many patients received several types of chemotherapies ${ }^{[16]}$. To date, the management of patients with GBM continues to harbor significant challenges, and comprehensive genetic screens of tumor tissues and signaling pathways have been explored to develop molecular-based targeted therapies ${ }^{[42]}$.

Besides age, KPS and radiotherapy prognostic factors, we also found that tumor size parameter has an influence on patient survival in our study. However, it was only significant in the multivariate analysis, as a continuous variable, and not significant in the univariate analysis.

In contrast, $\mathrm{Li}$ et al revealed that tumor maximal diameter (TMD) was a significant factor related to overall survival in the univariate analysis and not in the multivariate analysis by comparing groups with "TMD $<5 \mathrm{~cm}$ " versus "TMD $\geq 5 \mathrm{~cm}$ " ${ }^{[27]}$. In addition, Lutterbach et al suggested that a larger tumor diameter $(\geq 4 \mathrm{~cm})$ did not turn out to be an independent risk factor and indicated that the tumor location may be more important than tumor size for the prognosis of GBM patients ${ }^{[23]}$.

The extent of surgical resection in patients with newly diagnosed glioblastoma has been a well-documented prognostic factor for survival ${ }^{[11,14,32,43,44]}$. Okita et al showed that the extent of surgical resection is important, even in recurrent cases ${ }^{[44]}$. Our analyses do not show significant influence of extent of surgery on survival when compared survival time between the total and subtotal resection groups, and the partial and biopsy groups of newly diagnosed glioblastoma patients. The lack of significance of surgery could be due to the insufficient number of patients in the "total resection" group, only 12 cases.

Finally, we found that the clinical history delay factor had no significant influence on overall survival in both analyses. This is in agreement with Tugcu et al who revealed that neither duration of complaint nor clinical symptoms showed correlation with survival time ${ }^{[24]}$.

\section{Conclusion}

Our findings confirm the strong prognostic value of age, performance score, and treatment with radiotherapy for glioblastoma patients. Radiotherapy, KPS and tumor size were identified as independent prognostic factors of survival in our patients. Identifying different prognostic factors may help tailor specific treatment regimens to improve outcomes by developing a prognostic model which might be helpful to optimize patient selection for different treatment approaches.

\section{Acknowledgements}

We would like to acknowledge the entire staff of Neurosurgery and Radiotherapy departments for their contributions to this work. 


\section{Competing interests}

The authors declare that they have no conflict of interest.

\section{References}

[1] Ohgaki H, Dessen P, Jourde B, Horstmann S, Nishikawa T, et al. Genetic pathways to glioblastoma: a population-based study. Cancer Res. 2004; 64: 6892-6899. PMid:15466178 http://dx.doi.org/10.1158/0008-5472.CAN-04-1337

[2] Holland EC. Glioblastoma multiforme: the terminator. Proc Natl Acad Sci U S A. 2000; 97: 6242-6244. PMid:10841526 http://dx.doi.org/10.1073/pnas.97.12.6242

[3] Louis DN, Ohgaki H, Wiestler OD, Cavenee WK, Burger PC, et al. The 2007 WHO classification of tumours of the central nervous system. Acta Neuropathol. 2007; 114: 97-109. PMid:17618441 http://dx.doi.org/10.1007/s00401-007-0243-4

[4] Kleihues P, Ohgaki H. Primary and secondary glioblastomas: from concept to clinical diagnosis. Neuro Oncol. 1999; 1: 44-51. PMid:11550301

[5] Zhang X, Zhang W, Cao WD, Cheng G, Zhang YQ. Glioblastoma multiforme: Molecular characterization and current treatment strategy (Review). Exp Ther Med. 2012; 3: 9-14. PMid:22969836

[6] Stupp R, Mason WP, van den Bent MJ, Weller M, Fisher B, et al. Radiotherapy plus concomitant and adjuvant temozolomide for glioblastoma. N Engl J Med. 2005; 352: 987-996. PMid:15758009 http://dx.doi.org/10.1056/NEJMoa043330

[7] Theeler BJ, Groves MD. High-grade gliomas. Curr Treat Options Neurol. 2011; 13: 386-399. PMid:21499746 http://dx.doi.org/10.1007/s11940-011-0130-0

[8] Clarke J, Butowski N, Chang S. Recent advances in therapy for glioblastoma. Arch Neurol. 2010; 67: 279-283. PMid:20212224 http://dx.doi.org/10.1001/archneurol.2010.5

[9] Naydenov E, Tzekov C, Minkin K, Nachev S, Romansky K, et al. Long-term survival with primary glioblastoma multiforme: a clinical study in bulgarian patients. Case Rep Oncol. 2011; 4: 1-11. PMid:21537375 http://dx.doi.org/10.1159/000323432

[10] Thumma SR, Fairbanks RK, Lamoreaux WT, Mackay AR, Demakas JJ, et al. Effect of pretreatment clinical factors on overall survival in glioblastoma multiforme: a Surveillance Epidemiology and End Results (SEER) population analysis. World J Surg Oncol. 2012; 10: 75. PMid:22553975 http://dx.doi.org/10.1186/1477-7819-10-75

[11] Lacroix M, Abi-Said D, Fourney DR, Gokaslan ZL, Shi W, et al. A multivariate analysis of 416 patients with glioblastoma multiforme: prognosis, extent of resection, and survival. J Neurosurg. 2001; 95: 190-198. PMid:11780887 http://dx.doi.org/10.3171/jns.2001.95.2.0190

[12] Stark AM, van de Bergh J, Hedderich J, Mehdorn HM, Nabavi A. Glioblastoma: clinical characteristics, prognostic factors and survival in 492 patients. Clin Neurol Neurosurg. 2012; 114: 840-845. PMid:22377333 http://dx.doi.org/10.1016/j.clineuro.2012.01.026

[13] Niyazi M, Schwarz SB, Suchorska B, Belka C. Radiotherapy with and without temozolomide in elderly patients with glioblastoma. Strahlenther Onkol. 2012; 188: 154-159. PMid:22231634 http://dx.doi.org/10.1007/s00066-011-0026-7

[14] Habberstad AH, Lind-Landstrom T, Sundstrom S, Torp SH. Primary human glioblastomas - prognostic value of clinical and histopathological parameters. Clin Neuropathol. 2012; 31: 361-368. PMid:22939176 http://dx.doi.org/10.5414/NP300439

[15] Valduvieco I, Verger E, Bruna J, Caral L, Pujol T, et al. Impact of radiotherapy delay on survival in glioblastoma. Clin Transl Oncol; 2012.

[16] Mineo JF, Bordron A, Baroncini M, Ramirez C, Maurage CA, et al. Prognosis factors of survival time in patients with glioblastoma multiforme: a multivariate analysis of 340 patients. Acta Neurochir (Wien). 2007; 149: 245-252; discussion 252-243.

[17] Field KM, Rosenthal MA, Yilmaz M, Tacey M, Drummond K. Comparison between poor and long-term survivors with glioblastoma: Review of an Australian dataset. Asia Pac J Clin Oncol; 2013. http://dx.doi.org/10.1111/ajco.12076

[18] Yang T, Temkin N, Barber J, Geyer JR, Leary S, et al. Gross total resection correlates with long-term survival in pediatric patients with glioblastoma. World Neurosurg. 2013; 79: 537-544. PMid:23017588 http://dx.doi.org/10.1016/j.wneu.2012.09.015

[19] Hilmani S, Abidi O, Benrahma H, Karkouri M, Sahraoui S, et al. Clinicopathological Features and Molecular Analysis of Primary Glioblastomas in Moroccan Patients. J Mol Neurosci; 2012. PMid:22865003

[20] Marubini E, Valsecchi M, eds. Analyzing survival data from clinical trials and observational studies. Wiley: West Sussex; 1995.

[21] Fine HA. The basis for current treatment recommendations for malignant gliomas. J Neurooncol. 1994; 20: 111-120. PMid:7807189 http://dx.doi.org/10.1007/BF01052722

[22] Filippini G, Falcone C, Boiardi A, Broggi G, Bruzzone MG, et al. Prognostic factors for survival in 676 consecutive patients with newly diagnosed primary glioblastoma. Neuro Oncol. 2008; 10: 79-87. PMid:1799363 http://dx.doi.org/10.1215/15228517-2007-038

[23] Lutterbach J, Sauerbrei W, Guttenberger R. Multivariate analysis of prognostic factors in patients with glioblastoma. Strahlenther Onkol. 2003; 179: 8-15. PMid:12540979 
[24] Tugcu B, Postalci LS, Gunaldi O, Tanriverdi O, Akdemir H. Efficacy of clinical prognostic factors on survival in patients with glioblastoma. Turk Neurosurg. 2010; 20: 117-125. PMid:20401838

[25] Stark AM, Nabavi A, Mehdorn HM, Blomer U. Glioblastoma multiforme-report of 267 cases treated at a single institution. Surg Neurol. 2005; 63: 162-169; discussion 169. PMid:15680662 http://dx.doi.org/10.1016/j.surneu.2004.01.028

[26] Birol Sarica F, Tufan K, Cekinmez M, Sen O, Cem Onal H, et al. Effectiveness of temozolomide treatment used at the same time with radiotherapy and adjuvant temozolomide; concomitant therapy of glioblastoma multiforme: multivariate analysis and other prognostic factors. J Neurosurg Sci. 2010; 54: 7-19. PMid:20436394

[27] Li SW, Qiu XG, Chen BS, Zhang W, Ren H, et al. Prognostic factors influencing clinical outcomes of glioblastoma multiforme. Chin Med J (Engl). 2009; 122: 1245-1249.

[28] Jeremic B, Milicic B, Grujicic D, Dagovic A, Aleksandrovic J, et al. Clinical prognostic factors in patients with malignant glioma treated with combined modality approach. Am J Clin Oncol. 2004; 27: 195-204. PMid:15057161 http://dx.doi.org/10.1097/01.coc.0000055059.97106.15

[29] Gorlia T, van den Bent MJ, Hegi ME, Mirimanoff RO, Weller M, et al. Nomograms for predicting survival of patients with newly diagnosed glioblastoma: prognostic factor analysis of EORTC and NCIC trial 26981-22981/CE.3. Lancet Oncol. 2008; 9: 29-38. http://dx.doi.org/10.1016/S1470-2045(07)70384-4

[30] Balducci M, Fiorentino A, De Bonis P, Chiesa S, Manfrida S, et al. Impact of age and co-morbidities in patients with newly diagnosed glioblastoma: a pooled data analysis of three prospective mono-institutional phase II studies. Med Oncol. 2012; 29: 3478-3483. PMid:22674154 http://dx.doi.org/10.1007/s12032-012-0263-3

[31] Surawicz TS, Davis F, Freels S, Laws ER Jr, Menck HR. Brain tumor survival: results from the National Cancer Data Base. J Neurooncol. 1998; 40: 151-160. PMid:9892097 http://dx.doi.org/10.1023/A:1006091608586

[32] Allahdini F, Amirjamshidi A, Reza-Zarei M, Abdollahi M. Evaluating the prognostic factors effective on the outcome of patients with glioblastoma multiformis: does maximal resection of the tumor lengthen the median survival? World Neurosurg. 2010; 73: 128-134; discussion e116.

[33] Albert FK, Forsting M, Sartor K, Adams HP, Kunze S. Early postoperative magnetic resonance imaging after resection of malignant glioma: objective evaluation of residual tumor and its influence on regrowth and prognosis. Neurosurgery. 1994; 34 : 45-60; discussion 60-41.

[34] Fiorentino A, Caivano R, Chiumento C, Cozzolino M, Clemente S, et al. Comorbidity assessment and adjuvant radiochemotherapy in elderly affected by glioblastoma. Med Oncol. 2012; 29: 3467-3471. PMid:22580816 http://dx.doi.org/10.1007/s12032-012-0246-4

[35] Karnofsky DA, Burchenal JH. The clinical evaluation of chemotherapy agents. In: CM M, editor. Evaluation of chemotherapeutic agents. New York: Columbia Press; 1949: pp. 191-205.

[36] Stuschke M, Thames HD. Hyperfractionated radiotherapy of human tumors: overview of the randomized clinical trials. Int J Radiat Oncol Biol Phys. 1997; 37: 259-267. http://dx.doi.org/10.1016/S0360-3016(96)00511-1

[37] Floyd SR, Kasper EM, Uhlmann EJ, Fonkem E, Wong ET, et al. Hypofractionated Radiotherapy and Stereotactic Boost with Concurrent and Adjuvant Temozolamide for Glioblastoma in Good Performance Status Elderly Patients - Early Results of a Phase II Trial. Front Oncol. 2012; 2: 122. PMid:23087896 http://dx.doi.org/10.3389/fonc.2012.00122

[38] Fariselli L, Pinzi V, Milanesi I, Silvani A, Marchetti M, et al. Short-course radiotherapy in elderly patients with glioblastoma: feasibility and efficacy of results from a single centre. Strahlenther Onkol. 2013; 189: 456-461. PMid:23625362 http://dx.doi.org/10.1007/s00066-013-0346-x

[39] Johnson DR, O'Neill BP. Glioblastoma survival in the United States before and during the temozolomide era. J Neurooncol. 2012; 107: 359-364. PMid:22045118 http://dx.doi.org/10.1007/s11060-011-0749-4

[40] Fiorentino A, Balducci M, De Bonis P, Chiesa S, De Filippo L, et al. Can Elderly Patients With Newly Diagnosed Glioblastoma be Enrolled in Radiochemotherapy Trials? Am J Clin Oncol. 2013. PMid:23388566 http://dx.doi.org/10.1097/COC.0b013e3182868ea2

[41] Stewart LA. Chemotherapy in adult high-grade glioma: a systematic review and meta-analysis of individual patient data from 12 randomised trials. Lancet. 2002; 359: 1011-1018. http://dx.doi.org/10.1016/S0140-6736(02)08091-1

[42] Comprehensive genomic characterization defines human glioblastoma genes and core pathways. Nature. 2008; 455: $1061-1068$. PMid:18772890 http://dx.doi.org/10.1038/nature07385

[43] Ammirati M, Vick N, Liao YL, Ciric I, Mikhael M. Effect of the extent of surgical resection on survival and quality of life in patients with supratentorial glioblastomas and anaplastic astrocytomas. Neurosurgery. 1987; 21: 201-206. PMid:2821446 http://dx.doi.org/10.1227/00006123-198708000-00012

[44] Okita Y, Narita Y, Miyakita Y, Ohno M, Fukushima S, et al. Pathological findings and prognostic factors in recurrent glioblastomas. Brain Tumor Pathol. 2012; 29: 192-200. PMid:22331317 http://dx.doi.org/10.1007/s10014-012-0084-2 